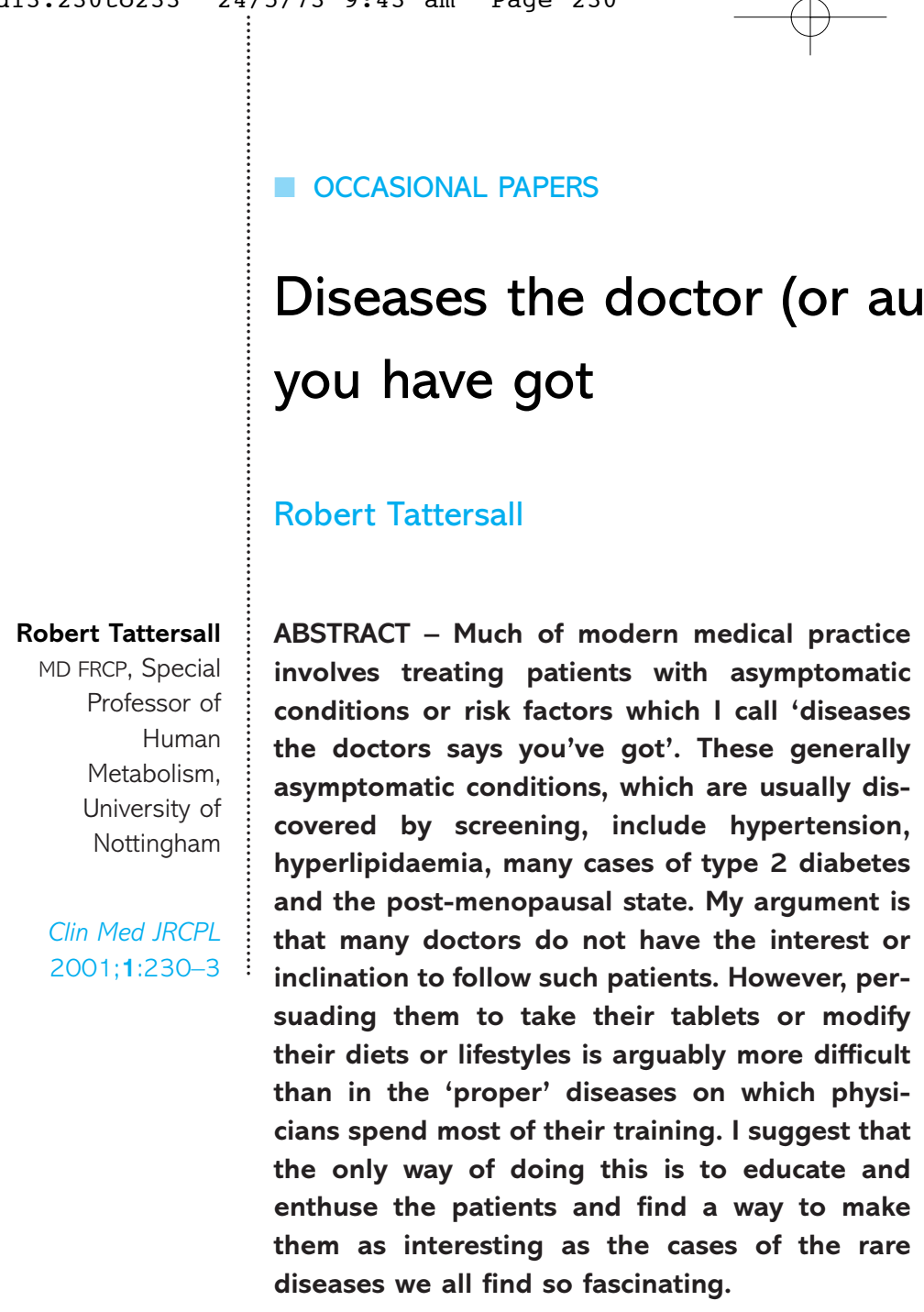

The focus of health policy for most of the 19th century was to get rid of dirt and pollution - a job for sanitary engineers. By 1900 it had shifted to personal preventive medicine - a job for doctors. Then, as now, doctors were fond of giving vague general health advice, especially to rich patients, such as 'take things quietly' or 'a change of air would do you good'. Some were more specific: William Osler found himself telling patient after patient with angina 'to eat less, smoke less, work less, worry less... live a godly life and avoid mining shares' ${ }^{1}$. (This sounds like good advice but is not evidence based!) Osler claimed that golf and the bicycle had materially improved the health of the young but warned that vigorous exercise was only suitable for those with young arteries not 'the senile contingent' (those over age 40 !). These lifestyle mantras are still being recited but during the past 20 years the focus has shifted to treatment of conditions which have the potential to cause harm in the future and of which the 'sufferer' is blissfully unaware until he or she attends a well man or woman check-up. These conditions include hypertension, hyperlipidaemia, many cases of type 2 diabetes and the postmenopausal state. I call them 'diseases the doctor says you've got' in contrast to conditions such as Crohn's disease and type 1 diabetes where symptoms force you to the doctor (Table 1). A third category, which does not concern us here, is diseases which other people know you've got.

'Diseases the doctor says you've got' challenge the traditional medical paradigm since most are biochemical abnormalities or risk factors rather than the 'proper diseases' doctors are trained to treat. Furthermore, health promotion and preservation poses different, and arguably more taxing, management problems. The question is who should do this work.

\section{The good old days}

In the good old days patients presented with proper illnesses. Clinicians used to say with pride 'we've got a ward full of fantastic pathology', an attitude which can still be heard over lunch in the doctors' mess. In the good old days the idea that one should treat asymptomatic disease was laughable. In 1939 Weiss satirised the treatment of hypertension as follows:

What has been done in an effort to reduce the blood pressure? Because of an ill founded idea that protein was responsible for hypertension and kidney disease, the patient was denied meat and eggs, and especially red meat, which for some reason was looked on with particular dread. His diet was rendered even more unpalatable by the withdrawal of salt. Sympathy would doubtless have been extended to this half-starved fellow except that he was probably not able to eat anyway, his teeth having been extracted on the theory that focal infection had something to do with hypertension ${ }^{2}$. Even before this he had sacrificed his tonsils and had had his sinuses punctured because of the same theory. In case some food had been consumed, the slight colonic residue was promptly washed out by numerous colonic irrigations, especially during the period when the theory of autointoxication was enjoying a wave of popularity. To add to his unhappiness he was often told to stop work and exercise. Of course, he was denied alcohol and tobacco as well as coffee and tea, and as a climax to the difficulties of this unfortunate person he may now fall into the clutches of the neurosurgeon, who is prepared to separate him from his sympathetic nervous system ${ }^{3}$.

While this is clearly satirical, as well as being written by someone with psychoanalytical leanings, it does make some important and enduring points: 
- Health promotion advice is often a child of its time and what is taught today may be ridiculed in twenty years.

- Lifestyle changes - no smoking, alcohol or coffee - are not popular with patients.

- Side effects of preventive treatment may seriously interfere with daily living as encapsulated in the apocryphal 'Doctor, if I follow your treatment will I live longer or will it just seem longer?'

\section{Does prevention work?}

This may seem a heretical question. However, according to an article in the Scientific American in 1995, only three of the preventive services evaluated by the Office of Technology Assessment paid for themselves; they were prenatal care for poor women, childhood immunisations and screening neonates for specific conditions such as phenylketonuria and hypothyroidism ${ }^{4}$. Many well-meaning interventions are simply a waste of time. Let us take three recent examples. In one study patients with angina were randomised to usual NHS care or usual plus 'personal health promotion from a trained nurse every four months for two years'. Exercise frequency increased in the intervention group at the end of two years but at five years there were no significant differences in blood pressure, weight, cholesterol, frequency of angina or restriction of activities ${ }^{5}$. In the second, an attempt was made to increase the frequency of regular exercise in a deprived area of Newcastle. Adults aged 40-65 were randomised to four different interventions, the most intensive of which was six interviews over six weeks plus vouchers for free access to leisure facilities. Short-term increases in activity at 12 weeks were not sustained at one year, regardless of the intensity of the intervention ${ }^{6}$. The results of the third example are summarised by its title, 'Failure of an intervention to stop teenagers smoking' ${ }^{7}$. As with exercise and trials of other healthy behaviours, early gains from anti-smoking programmes are quickly lost once the initial enthusiasm has worn off.

A cynic might say that the reason why doctors feel that nurses are ideally suited to this work is that it is so obviously unprofitable.

\section{Staying sane}

There are two ways of managing asymptomatic conditions. One, which I have reason to think is common in the newly invented

\section{Key Points}

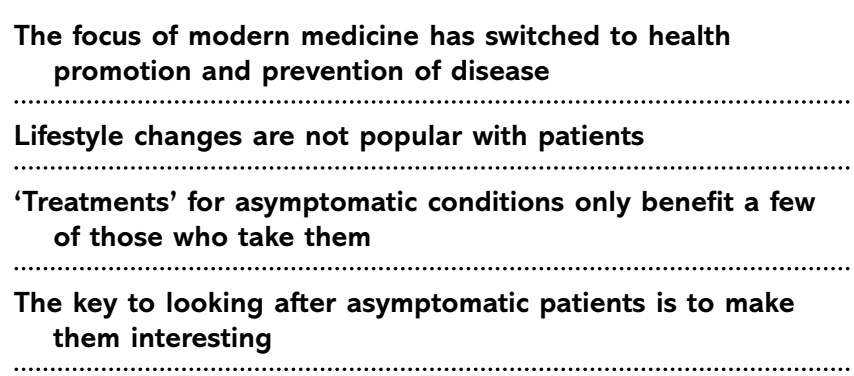

specialty of vascular medicine, is to put the patient through the autoanalyser a day or two earlier, and then spend the appointment poring over printouts, tut-tutting, and doubling the dose of the statin (which the patient is not taking anyway). The second is to make the patient interesting, even if the disease is dull as ditchwater. Frank Davidoff, in his highly recommended book Who has seen a blood sugar?, put it well:

It is one thing to see twenty different cases of diabetes in the course of a week; it is quite another to see twenty different people as patients, all of whom happen to have diabetes. In every case, the very same biological disease 'lives' in a different person, and the disease expresses itself differently in every one of them. Learning about what makes these individual patients 'tick' biologically and psychologically; figuring out how best to interact with each of them; deciding how best to negotiate, to develop therapeutic alliances, to use language effectively - all provide potentially endless sources of interest. ${ }^{8}$

This surely applies equally to doctors and nurses and is the only way to survive the grind of following asymptomatic patients. It also has the advantage that compliance will probably be better if the patient feels he/she is being seen as a person rather than a printout.

\section{Compliance}

Unfortunately, even with 'diseases you know you've got' compliance is a major problem once the initial novelty has worn off. A major difficulty is that you can't necessarily feel the treatment working and paradoxically you may even feel worse if it is; the classical example of the latter situation is the person with type 1 diabetes striving for normoglycaemia who has repeated hypos. The problem is not confined to medicine. Apparently cosmetics

Table 1. My classification of disease

\begin{tabular}{lll}
\hline Diseases the doctor says you've got & Diseases you know you've got & Diseases other people know you've got \\
Hypertension & Type 1 diabetes & Attention deficit hyperactivity disorder \\
Hyperlipidaemia & Asthma & Alzheimer's disease \\
Impaired glucose tolerance & Inflammatory bowel disease & \\
Gestational diabetes & Cystic fibrosis \\
& Parkinson's disease \\
Postmenopausal state (asymptomatic) & Menopausal symptoms
\end{tabular}


companies find that their customers need to feel the effect of a treatment. A spokesperson is quoted as saying that in an anticellulite product, 'you might want to include an element which will make the skin throb. It's sending a message that the product works ${ }^{9}$. An antihypertensive drug which increased sexual potency would be a surefire winner!

In all illnesses a third of patients, irrespective of intelligence or social class, do not take their medication as prescribed or ignore the doctor's advice in other ways ${ }^{10}$. Lipkin put it well when he remarked that 'thoughtful physicians in contact with patients for any length of time become impressed with the deep unreason with which many approach medical care'11. I learned this lesson as a house physician when I looked after one of my boss's special patients, a cabinet minister, who in addition to having conventional medical treatment was sending his urine and faeces to be put in a black box! Another important point is that doctors grossly underestimate rates of non-compliance and can only identify those who make it blindingly obvious. In general, compliance is best when the patient regards the illness as serious and himself or herself personally at risk. Conversely, it is worse when it involves complicated regimens to be kept up over a long period of time and substantial degrees of behaviour change. This is even more of a problem with 'diseases the doctor says you've got' where those responsible for advising/supervising should remember that, as was said in the context of arsenical treatment of syphilis, '[It] is a long, slow painful and expensive grind which can be sold to be victims of the disease only by our utmost in educative and persuasive power ${ }^{12}$.'

\section{What does the consumer want to buy?}

Ideally a cure, but failing this, a convincing explanation of why treatment of an asymptomatic disease is better than just carrying on regardless. What he/she needs is:

1. As accurate a diagnosis as possible; ie, is it type 1 , type 2 or some other variety. Is it heritable?

2. An indication of the likely prognosis. Is he a run of the mill case or are there special features? Suppose he refuses all treatment, what will happen? If the doctor's advice is followed to the letter, might there still be complications? If so, what?

3. A management plan. What are his responsibilities? How can he monitor his progress? What danger signs would indicate the need to seek professional help? If restrictions are going to be put on daily activities, what is the rationale for them? Ideally this should be written down and given to the person ${ }^{13}$.

4. Some idea of the risk/benefit ratio. If I take hormone replacement therapy, how much will it reduce my risk of a fracture or heart attack and how much will it increase my risk of breast or uterine cancer? It is particularly important that relative and absolute risks are quoted. For example, in a news story in the USA, a bisphosphonate was splashed across the front pages with the message that it reduced the frequency of hip fractures by $50 \%$ - what was not mentioned was that this reduced the event rate from 2 to $1 \%{ }^{14}$. Advertisements in medical journals, except, of course, Clinical Medicine, often convey similarly misleading messages based on relative risk reduction.

5. Continued follow-up and feedback. A competent person(s) to oversee progress and give practical help and emotional support if there are difficulties. Questions should be answered truthfully in jargon-free language and he or she should be told where to find out more.

I suggest that treatment of asymptomatic and chronic diseases often fails because these conditions are not met in the first place so that the customer is neither engaged nor empowered. Indeed, he may even find it difficult to accept that he has the condition in question.

\section{Who should sell the treatment/intervention?}

The conventional view is that the selling should be done by the doctor with the after-sales service being provided by the nurse. It is undoubtedly an old-fashioned, and probably politically incorrect, view but I strongly believe that the initial diagnosis should be given by someone the consumer respects and is somewhat in awe of. Richard Asher put it well, as he usually did, when he said, 'Confidence is invaluable because if you are certain you are right and if you can convince the patient that you are right then whether you really are right or not often makes very little difference ${ }^{15}$.' Discussing his own case, Franz Inglefinger, a gastroenterologist and editor of the New England Journal of Medicine, complained that he did not want to make choices about his own treatment but would prefer an experienced physician to do it. This was despite the fact that the disease he had was one he had specialised in. He wrote:

it follows that the patient has to believe in the physician, that he has confidence in his advice and reassurance, and in his selection of a pill that is helpful (though not curative of the basic disorder). Intrinsic to such a belief is the patient's conviction that his physician not only can be trusted but also has some special knowledge that the patient does not possess. He needs, if the treatment is to succeed, a physician whom he invests with authoritative experience and competence. He needs a physician from whom he will accept some domination. If I am going to give up eating eggs for the rest of my life, I must be convinced, as an ovophile, that a higher authority than I will influence my eating habits. I do not want to be in the position of a shopper at the Casbah who negotiates and haggles with the physician about what is best ${ }^{16}$.

What is being sold to the patient in the case of 'diseases the doctor tells you you've got' is a treatment which will work in a statistical sense but which will not improve, and may be detrimental to, well-being.

Suggesting that the initial message needs to be given by a powerful authoritative figure is not to deny that the patient should be empowered, neither does it mean that the teller has to be a bow-tied, elderly, physician. It could perfectly easily be a female general practitioner or male practice nurse, provided that they have the appropriate gravitas and knowledge. It is their 
educative, persuasive and motivational power which makes them appropriate or otherwise.

\section{References}

1 Michael Bliss. William Osler, a life in medicine. Oxford: Oxford University Press, 1999:273.

2 The doctrine of focal infection originated with Frank Billings in Chicago in 1915 and was adopted widely. A standard textbook recommendation for the treatment of any disease of unknown aetiology was to search for and remove any possible focus of infection. The result was that during the next quarter of a century millions of unnecessary dental extractions and surgical operations were performed.

3 Weiss E. Recent advances in the pathogenesis and treatment of hypertension - a review. Psychosom Med 1939;1:180. In 1925 Rowntree and Adson reported a case of malignant hypertension treated and improved by bilateral lumbar sympathectomy and the operation was relatively widely used until the early 1950s.

4 Leutwyler K. The price of prevention. Sci Am April 1995;98-103.

5 Cupples ME, McKnight A. Five year follow up of patients at high cardiovascular risk who took part in randomised controlled trial of health promotion. Br Med J 1999;319:687-8.

6 Harland J, White M, Drinkwater C, Chinn D, et al. The Newcastle exercise project: a randomised controlled trial of methods to promote physical activity in primary care. Br Med J 1999;319:828-32.
7 Reid D. Failure of an intervention to stop teenagers smoking. $\mathrm{Br} \mathrm{Med} \mathrm{J}$ 1999;319:934-5.

8 Davidoff $\mathrm{F}$. The dilemma of the uninteresting patient. In: Who has seen a blood sugar? Philadelphia: American College of Physicians, 1996:68. This excellent book is not all, or even mainly, about diabetes.

9 The Independent 1999, Sept 16, p. 10.

10 Haynes RB, Taylor DW, Sackett DL (eds) Compliance in health care. Baltimore: Johns Hopkins Press, 1979.

11 Lipkin M. The care of patients: perspectives and practices. New Haven, CT: Yale University Press, 1987.

12 Quoted by Benedek TG and Ehrlen R. The scientific environment of the Tuskegee study of syphilis, 1920-1960. Perspect Biol Med 1999;43:1-30.

13 Tattersall RB. Writing to patients. Diabet Med 1990;7:917-19.

14 Moynihan R, Bero L, Ross-Degnan D, Henry D, et al. Coverage by the news media of the benefits and risk of medications. N Engl J Med 2000; 342:1645-50.

15 Richard Asher. Talking sense. Edinburgh: Churchill Livingstone, 1986: 117.

16 Inglefinger FJ. Arrogance. N Engl J Med 1980;303:1507-11.

Address for correspondence: Professor R Tattersall, Curzon House, Curzon Street, Gotham, Notts NG11 OHQ.

E-mail: robert.tattersall@virgin.net.

\section{Medical rehabilitation for people with physical and complex disabilities}

\section{A report from the Royal College of Physicians Committee on Rehabilitation Medicine}

The past ten years have seen significant improvements in the clinical techniques and technical resources that are effective in rehabilitation. In addition, the advances in medical treatment, the survival of more people into old age and changes in social behaviour and expectations have all rekindled an awareness of the need to promote well-being and social participation, irrespective of the residue of disease and injury. Thus rehabilitation should be an important facet of modern medicine. The specialty of rehabilitation medicine was created comparatively recently but despite its success and continuing growth, it is not widely understood by the medical profession or the wider world. Moreover there are insufficient resources and a lack of organisation which mean that medical advances are often not available to disabled people to meet their needs and to put them back on the route to independence.

This report outlines current practice in rehabilitation medicine, indicating the skills needed by the rehabilitation specialist and stressing the crucial role of multidisciplinary teamwork - both among clinicians and other health care professionals. It sets out what is required for an effective rehabilitation service in terms of both organisation and resources, and addresses recommendations to commissioners of health care, medical educators, NHS managers and doctors themselves. It is hoped that this report will bring greater understanding of rehabilitation medicine and lead to a less remote and fragmented service for disabled people.

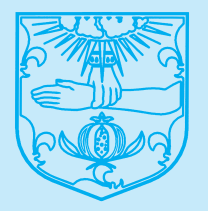

AVAILABLE FROM THE ROYAL COLLEGE OF PHYSICIANS

Published May 2000 ISBN 1860161332 A4 report, soft cover, 42 pages

Price: UK $£ 12.00$, overseas $£ 14.00$ (prices include postage and packing) 